\title{
Educational Reform on Landscape Design under the Background of Digital Era
}

\author{
Yuhan Wu \\ Department of Landscape Architecture, Suzhou Polytechnic Institute of Agriculture, China
}

\begin{abstract}
The explosive growth of global data and the massive aggregation of information have a very great impact on the world's social life and educational teaching approach. Facing the challenge of smarter landscape, this paper will combine the construction education reform pattern of landscape teaching and future prospects under the background of digital landscape design with the support of advanced science and technology. This article can be referenced to constitute syllabi for systemic landscape courses for future education in higher institutions.
\end{abstract}

Keywords: digital landscape; educational reform; landscape design

\section{Introduction}

In the context of the digital era, how to use educational technology through group wisdom to achieve the sustainable development of educational approach, continuous innovation and research progression on educational teaching of landscape design could be of great significance. Quantitative research based on artificial intelligence and big data is helping and optimizing decisions making of landscape architects and professional learners. Nowadays, the educational teaching research topics are all inclusive, focusing on technology utilization and interdisciplinary communication. At the end of the twentieth century, the landscape industry has formed a consensus that digital landscape simulators had finally attained the technical capability to 'photograph our future' ${ }^{[1]}$.

\section{Research Background and Challenges of Digital Landscape Teaching}

A considerable number of colleges and universities have been studying in the integration of this cutting-edge technology in the teaching system of digital landscape architecture. The department of landscape architecture of the Anhalt University of Applied Sciences, Germany, with more than 500 major students is the most famous and influential one. It has one of the largest department of landscape architecture in the world. Its teaching feature is always to let students master the latest computer technology tools, which also lays the foundation for its successful holding of the international frontier conference, the International Digital Landscape Architecture Conference ${ }^{[2]}$.

In mainland China, many universities are actively exploring the integration and application of digital landscape technology. Southeast University has taken digital landscape technology as a separate training direction of landscape architecture discipline, and has successfully held three sessions of China Digital Landscape International Forum, which has become the vane of digital landscape technology teaching in mainland China. At present, digital landscape technology is the research hotspot of landscape architecture major in colleges and universities, and it is the forefront of the discipline vertical extension.

\section{Innovative Teaching method}

Nowadays, with the popularization of Internet and the continuous upgrading of related software, the acquisition of 
landscape data is not just limited to landscape professionals. The potential learners can easily access a wide range of rich data resources as well. And landscape design practitioners use such as OSM (Open Street Map) data, DEM (Digital Elevation Model), urban POI (Point of Information) data, remote sensing technology, aerial survey technology, 3D scanning technology and others to quickly clarify the geographical characteristics of the site, improving the accuracy of investigation, design and construction, which have direct and obvious contact with digital landscape.

\subsection{Research on Teaching Pattern of Digital Landscape}

Extensive literature and professional research has shown that landscape industry education has evolved from the 1.0 classical traditional era, the 2.0 industrial revolution human-oriented era, the 3.0 ecological era emerging after World War II to the 4.0 digital intelligent landscape era. The core construction logic of digitization education is the binary code translation process based on computer language and computer technology. Without the intervention of any subjective evaluation, digitization enables us to make data collection, data analysis, data simulation, scheme comparison, implementation and construction more optimized and efficient, realize digitization of all segments in the meantime.

\subsection{Construction Pattern of Digital Landscape Teaching}

Generally speaking, the whole digital landscape teaching logic should have at least the following constituent elements: the collection of landscape data, the landscape data analysis, the simulation of landscape scheme, the digital construction of landscape design, and the performance assessment of landscape project.

\subsubsection{Data acquisition}

Data collection mainstream methods nowadays of digital landscape architecture teaching could be: remote sensing technology, aerial survey technology, three-dimensional scanning technology, etc. In addition, there are photo-grammetry program can be used to generate the work-flow of digital elevation model; LIDAR (Light Detection and Ranging) and SAR (Synthetic Aperture Radar), photo-grammetry and modeling software Agisoft PhotoScan Pro etc. These kinds of software are pretty suitable for hydro-logical and geographical analysis of relatively small design sites. Piotr and Agnieszka use neither satellite nor aerial images, but take near-infrared photos to calculate Normalized Difference Vegetation Index (NDVI) and enhanced vegetation index (EVI), which are effective new methods for information extraction. The application of data collection technology not only provides more objective and comprehensive data, but also presents the traditional dispersal environmental information in an even more concise way, thus providing landscape design learners new perspectives for landscape architecture design.

\subsubsection{Data analysis}

The data analysis methods of contemporary landscape architecture teaching are constantly updated and iterated. The NK landscape methodology, as it provides novel ways to formally analyze core organizational issues such as bounded rationality, felicity, interdependence, and organizational search allows modeling the performance of a general class of systems. Although originally developed to model biological systems [4]. ENVI 、 ERDAS、Dethmap 、 Fragstats Fluent 、Urbanwind and other digital software platforms provide support for landscape design analysis including geographic analysis, spatial analysis, habitat analysis. These new means and software are extremely effective teaching tools, their emergence also put forward higher professional requirements for teachers. Being as a teaching implementer, follow the trend of the industry, continuous learning in time and get involved into the industry is necessary.

\subsubsection{Scheme simulation and construction approach}

By inputting the $3 \mathrm{D}$ terrain model into the construction machinery terminal, the full automation of terrain construction can be realized, which not only saves manpower and material resources, improves the construction efficiency, but also has the features of efficiency and fastness. The digital construction of landscape architecture is to 
reshape the whole construction process through the collaborative work of digital technology based on informative scientific 3D printing technology. 3D printing is also known as rapid prototyping equipment, has been widely used in landscape education recent years. Using it students have increased their studying passion, and the effect of teaching was improved.

\subsubsection{Performance assessment}

In the analysis and evaluation phase, digital landscape also has a significant usage in the field of ecology. The performance assessment of road landscape results can be evaluated by using surface runoff control, rainwater collection, resource utilization, system habitat optimization, system economy and other indicators. GIS software with an outstanding analysis ability, can play a key role in evaluating land vulnerability, suitability, risk stratification, land planning and vegetation planning performance.

\section{Conclusions}

The author thinks that it is not enough to classify the digital landscape technology teaching merely from the above technical level. Information technology has the inherent advantages of visualization and collaboration, which greatly improves the efficiency of collaborative integration and overall project management in landscape architecture design process. From the perspective of collaboration and rapid exchange of information among various disciplines, based on specific technologies, teaching application level should have at least three phases in hierarchical relationship : collaborative phase _ integrated phase__ application phase. Digital landscape technology is still developing rapidly, there are many educational reform research gaps to be supplemented, in which worthy of in-depth study and research.

\section{References}

[1] D. Mullerova and M. Williams. (2019). Satellite Monitoring of Thermal Performance in Smart Urban Designs. Remote Sens, 11(19), 2244.

[2] Liu S. and Zhang S.W. (2015). Review on Digital Landscape Technology Research-Study on Digital Landscape Architecture Conference. Chinese Landscape Architecture, 02(45-50).

[3] Guo D.J., Gao W. and Lee T. (2018). Teaching Reform of Landscape Architecture Based on Digital Landscape Technology: a Case Study of Landscape Architecture Specialization of SCAU. Landscape Architecture Study, Vol.40/185, 04(28-29).

[4] Csaszar, F.A. (2018). A Note on How NK Landscapes Work. J Org Design, 06. 